system. The following contribution, by P. M. Laughton and R. E. Robertson, is closely related and considers the effect on equilibria and reactions. Once again the data refer to $\mathrm{H}_{2} \mathrm{O}$ and $\mathrm{D}_{2} \mathrm{O}$.

J. F. Garst, in his chapter, deals with the variations in rate and equilibria of organo-alkali compounds in protic and aprotic solvents. The ethers are singled out for particular detail. The volume is concluded by a very brief appendix by the editors, listing the recommended methods of purifying selected solvents.

Taken overall, the book seems to have particular appeal to the specialist interested in the application of the methods of physical chemistry to the problem of solution behaviour. Perhaps its specialist interest is reflected in its high price.

J. A. Salthouse

\section{FLUORIDE POISONING}

Toxic Properties of Inorganic Fluorine Compounds

By R. Y. Eagers. Pp. x+152. (Elsevier: Amsterdam, London and New York, 1969.) 55s.

Since the publication of Largent's excellent work (Fluorosis, Ohio State University Press, 1961) on the metabolism and toxicology of inorganic fluorine compounds, much information has been published on the subject which, with earlier works, is condensed in the 118 pages of this monograph. This book is best where it is more condensed, as in the scctions on effects on insects, plants and bacteria or when discussing endomic fluoride poisoning in humans and in animals. The text is vague, repetitive and disorganized when the author tries to express his own ideas as in the major part of the chapter on human intoxications. His definitions are often inaccurate or ambiguous. Thus on page 8 , the words suggest that acute fluoride poisoning from inhalation is not an industrial hazard although it may result from atmospheric pollution. In the chapter on acute poisoning (page 25) it is stated that "Acute fluoride poisoning by inhalation is essentially an industrial hazard", yet he goes on to say, "Normally, fluoride poisoning by inhalation may be described as chronic rather than acute. . ". Sometimes even the subtitles are misleading, as under the heading of "Absorbed Fluorides". Here the author discusses the effect of exposure by the dermal ronte, but, hypnotized by the drive to marry title and material, he opens this section with the surprising staternent that "Acute fluoride poisoning by absorption usually implies that the fluoride is absorbed through the skin as a result of local contact", but immediately proceeds, "Strictly speaking, all acute fluoride poisoning is the result of absorption", and then explains that ingested fluoricle is absorbed through the gastrointestinal tract and inhaled fluoride is absorbed through the respiratory tract.

This disorganized compilation includes much repetition and the separation of logically inseparable parts. Thus fluorides are characterized and their threshold limits are given on pages 4-7 and again on pages 76-80. Acute, subacute and chronic animal experiments are reviewed in the second chapter entitled "Effects on Animals" under the subtitle of "Acute Poisoning" and in the third chapter on "Other Effects" under the subtitle of "Physiological Effects". This latter section is inserted between "Effects on Plants" and "Effects on Bacteria". The characterization of some of the fluoride compounds is in many cases too imprecise, and because preventive measures are proposed for some but not the other compounds, the reader might believe that these lattor may be handled without risk.

The monograph may serve a useful purpose as a collection of 730 references, but the reader is advised to use only those pages and paragraphs in which the donsity of reference numbers is above a cortain threshold limit.

L. MAGos

\section{FUNGAL TOXIN}

Aflatoxin

Scientific Background, Control and Implications. Edited by Leo A. Goldblatt. (Food Science and Technology : a Series of Monographs.) Pp. xii +472. (Academic Press: New York and London, October 1969.) 201s.

Althotar the effects of mycotoxins have been observed for many years, comparatively little was known about their cause. From 1960 onwards this state of affairs has been dramatically altered as a result of the large-scale outbreak of a mycotoxicosis among turkey poults, which was known as "Turkey X" disease. The cause of "Turkey $\mathrm{X}$ " disease was eventually traced to the presence of a group of mycotoxins, in a groundnut-based feed contaminated with a strain of the mould Aspergillus flavus. The group name given to these mycotoxins was "aflatoxin". In addition to their toxic properties the aflatoxins were shown to be highly carcinogenic to many species. Since that time many research workers have expended a tremondous amount of effort in solving the problems associated with these compounds, and the net result of this work, which comprised more than five hundred papers by 1968, has been presented in this book under the editorship of Dr L. A. Goldblatt.

It is understandable that in attempting to produce a work on such a diversified subject, there must be a number of authors involved, and it is unavoidable that in a number of the contributions there is a tendency for repetition of the information.

The content of the book reflects the wide range of disciplines involved in solving the aflatoxin problem. The topics covered are dealt with in a total of fifteen chapters and they include the chemistry, production, assay, effects, metabolism and detoxification of the aflatoxins. The first chapter is a general introduction by the editor, and the subsequent ones contain a large amount of evidence and information, which in many cases is presented in a very useful tabular form. Another contribution is a list of precautionary measures to be taken when handling aflatoxins. These precautions should be made mandatory for all persons engaged in aflatoxin work, for it now seems extremely likely that aflatoxins are carcino. genic for man. In this latter connexion it is reassuring to read that a great deal of thought has been given to the protection of consumers from the aflatoxins. With this point in mind an appendix is included which contains a voluntary code of practice, currently in operation in the United States, for marketing and distribution of groundnuts.

Although the book is ostensibly about the aflatoxins, there are several chapters which contain information concerning fungal spoilage of food, and mycotoxins in geners.1. These generalizations help to place the aflatoxin problem in perspective, for, after all, the aflatoxins constitute only a few of the known mycotoxins. In fact, it is claimed that some of these other mycotoxins have at least equal importance to that of the aflatoxins themselves.

There is no doubt that, because of the authoritative and intensive manner in which this book has been com. piled, it will remain a standard text on the subject of aflatoxins for many years to come. M. F. DUTros

\section{YEAST BIOLOGY}

The Yeasts

Vol. 1: Biology of Yeasts. Edited by Anthony H. Rose and J. S. Harrison. Pp. xiii +508 . (Academic Press: London and New York, November 1969.) 140s; $\$ 19.50$.

YwASTS are constantly impinging on our daily life and they do so probably to a greater degree than other microorganisms. Not only are these organisms the exploited industrial slaves of baking, brewing, wine and cider 